\title{
DIETARY FACTORS AFFECTING FIRMICUTES AND BACTEROIDETES RATIO IN SOLVING OBESITY PROBLEM: A LITERATURE REVIEW
}

\author{
Deandra Ardya Sutoyo ${ }^{1}$, Dominikus Raditya Atmaka ${ }^{*}$, Lisandra Maria G. B. Sidabutar ${ }^{2}$ \\ ${ }^{1}$ Health and Nutrition Department, Faculty of Public Health, Universitas Airlangga, Surabaya, Indonesia \\ ${ }^{2}$ Institute of Nutrition, Mahidol University, Salaya, Thailand \\ *E-mail: dominikus.raditya@fkm.unair.ac.id
}

\begin{abstract}
Obesity is caused by several factors. Gut microbiota composition is known to be one of the factors to play a role in modulating the obesity process. Nutrient factors and bioactive compounds from food can influence and help in modifying the gut microbiota composition, especially Firmicutes and Bacteroidetes. The purpose of this article is to discuss how significant the role of nutrients and other bioactive compounds on Firmicutes and Bacteroidetes ratio in solving the obesity problem. This article was compiled based on the literature search in the last ten years, related to nutrients and bioactive compounds influence Firmicutes/Bacteroidetes ratio in obesity. The results from several literature searches provided evidence that alteration in gut microbiota composition was linked to the increase of body weight through metabolic pathways, which was characterized by the increasing number of Firmicutes, the decreased number of Bacteroidetes, and an increase in Firmicutes/Bacteroidetes ratio. The increasing number of Firmicutes could induce short-chain fatty acid (SCFA) production and lead to more energy harvesting. Several dietary factors from fiber and amino acid, as well as bioactive compounds from an organic acid and polyphenol compounds, could influence the gut microbiota composition by reducing the Firmicutes level and increasing Bacteroidetes. The gut microbiota composition, especially Firmicutes and Bacteroidetes, could be induced by modifying diet enriched with fiber, polyphenol compounds, and other specified nutrients.
\end{abstract}

Keywords: obesity, dietary factors, gut microbiota, F/B ratio

\section{INTRODUCTION}

The obesity problem has developed rapidly. Nowadays, obesity has become a global health problem that affects more than a third of the world's population. According to WHO (2015), 1.9 billion adolescents worldwide are categorized as overweight and 600 million adolescents are considered obese. The main causes of obesity are an increase in energy intake and low physical activity (Gerber, 2014; Whitney \& Rolfes, 2013). Besides, environmental, psychological, genetic, and lifestyle factors also have implications in the development of obesity, including the role of gut microbiota (Gerber, 2014; Davis, 2016).

Gut microbiota is described as a collection of organisms that live in the human gastrointestinal tract. Most of the gut microbiota are included in the Firmicutes and Bacteroidetes phyla (Power et al., 2014). The role of microbiota in the human body is to help in the food digestion process, to regulate the immune system, and to provide the protection needed from pathogenic bacteria (Dietert, 2015). The microbiota composition of each individual varies and can change following age, diet, symbiotic consumption, antibiotics, drugs, disease condition, and genotypes (Chen et al., 2014).

Moreover, gut microbiota, as the regulator of the digestion process, can affect and intervene in the metabolism process by increasing energy production from the diet and also regulating the composition of fatty acid tissue, which contributes to the obesity process (Cani et al., 2012). Several studies stated that alteration in the gut microbiota composition (the increasing Firmicutes and Bacteroidetes ratio) which is influenced by dietary factors also plays a big role in the obesity process (Davis, 2016; Ley et al., 2006). A diet which contains the low-fat polysaccharide to a diet high in fat and sugar alters the structure and the 
composition of the gut microbiota which can also affect the metabolic pathways and microbiome gene expression (Moschen et al., 2012). Dietary factors, such as the nutrients and bioactive compound from food, contributes to the direct and indirect effects on the gut microbiota. Dietary factors can directly promote or inhibit the microbiota growth, and increase the capability to harvest energy (Korem et al., 2015). Also, bioactive compounds from food can indirectly shape the gut microbiota and affect the immunity (Li et al., 2011). For instance, vitamin $\mathrm{D}$ is required to be the protection of gut mucosal defense against pathogens ( $\mathrm{Su}$ et al., 2016).

Firmicutes and Bacteroidetes ratio tends to increase in people with obesity and overweight (Kasai, 2015). The study conducted by Ley et al. (2006) obtained that a diet with low-calorie composition in obese subjects changed the balance of the Firmicutes and Bacteroidetes ratio, or the $\mathrm{F} / \mathrm{B}$ ratio, to a level comparable to individuals with normal weight. $\mathrm{F} / \mathrm{B}$ ratio is related to the increase of energy production from the fermentation in the colon which can cause the increase of SCFA production and contribute more energy. Another study by De Filippo et al. (2010) stated that there were differences in the $\mathrm{F} / \mathrm{B}$ ratio in African children, who consumed food high in low-fat fiber, and Italian children, who consumed food high in fat and protein. The F/B ratio decreased with weight loss because of the low-calorie diet intake. These results emphasize that diet and nutrient intake influence the formation of the gut microbiota composition (Scott et al., 2008). Some other studies also show that food or diet is the source of energy for gut microbiota which can affect and have implications for the balance and functions of the human body (Graf et al., 2015). Gut microbiota also has rapid responses to changes in diet and dietary habits (David et al., 2014).

This review focuses on the current evidence of the association between $\mathrm{F} / \mathrm{B}$ ratio and obesity as well as the dietary factors influencing the changes of it, also to discuss the role and influence of dietary factors (nutrients and bioactive compounds from food) in solving the obesity problem through the gut microbiota composition, which is $\mathrm{F} / \mathrm{B}$ ratio.

\section{METHODS}

The literature search was carried out on research articles (including observational studies namely cross-sectional, cohort, case-control, and experimental studies) within the last ten years (2009-2019) using the electronic database

PubMed/Medline, Scopus, Science Direct, and Google Scholar. Researches published before the period were also included in relevancy and can be justified. The main keyword used in the search for literature studies are diet; obesity; dietary factors; and gut microbiota, or Firmicutes/Bacteroidetes in open- and closed-access international journals and written in English. The researches chosen

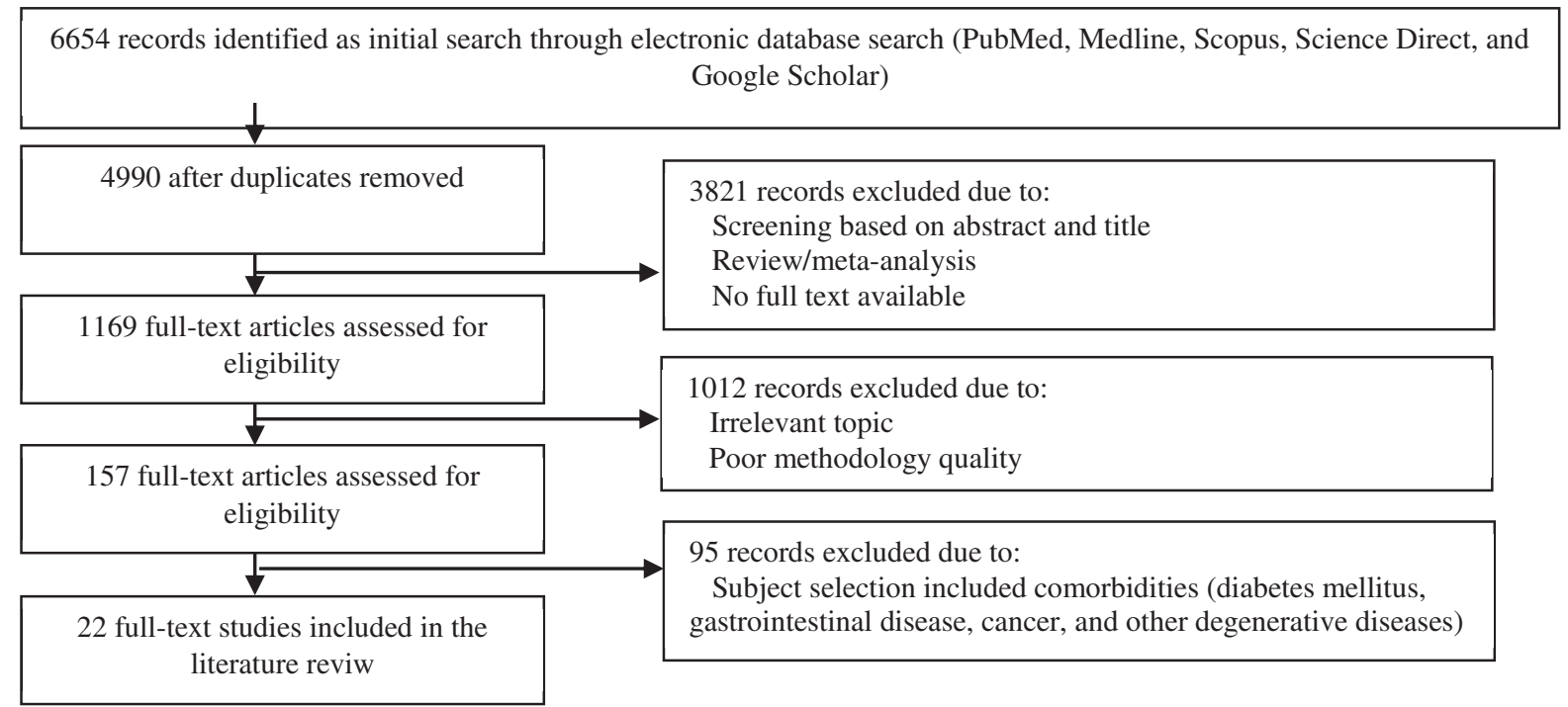

Figure 1. Diagram flow of included and excluded studies for the review 
must meet the inclusion criteria which show the role and influence of dietary factors in obesity and gut microbiota, both in human and animal studies. The study was excluded if the subject selection included other comorbidities such as diabetes mellitus, gastrointestinal disease, cancer, and other degenerative diseases, and if the study was also literature, systematic review, or metaanalysis. All articles found and chosen were then studied profoundly.

\section{RESULTS AND DISCUSSIONS}

\section{Literature Search}

A total of 22 research studies results were included in the review and further explained in Tables 1 and 2. Ten articles were analyzed according to the association between the $\mathrm{F} / \mathrm{B}$ ratio and obesity, while twelve articles were analyzed regarding the dietary role in the alteration of the $\mathrm{F} / \mathrm{B}$ ratio.

\section{Association of F/B ratio and Obesity}

Obesity is known as a disorder caused by various factors, one of them is the energy imbalance, namely energy intake that exceeds the individual's energy expenditure (Hill et al., 2012). Gut microbiota is known to have an important role in regulating energy balance (Apovian, 2016). The human gut is composed of five phyla, namely Bacteroidetes, Firmicutes, Actinobacteria, Proteobacteria, and Verrucomicrobia. Mainly, Bacteroidetes and Firmicutes are the ones dominating it around $90 \%$ of the total species (Qin et al., 2010; Tang et al., 2017). This composition of gut microbiota can alter between lean and obese individuals. Obese and lean individuals have different compositions of microbiota, especially the differences in the ability to convert the energy from food which is then stored as fat (Turnbaugh et al., 2009). Alteration in the microbiota composition is one of the causes of obesity; one of them is a significant change in the composition of grampositive microbiota, or Firmicutes, and gramnegative microbiota, or Bacteroidetes (Sonnenburg et al., 2016).

Research conducted by Koliada et al. (2017) stated that the composition of Firmicutes increases and Bacteroidetes decreases with an increase in
Body Mass Index (BMI). Firmicutes increase the effectiveness in the calorie absorption by modulating and increasing the capacity for energy harvesting and the metabolic degradation rate of a given energy source, which results in more weight gain (Turnbaugh et al., 2006; KrajmalnikBrown et al., 2012). Moreover, the increasing abundance of Firmicutes can also increase the number of lipid droplets which will increase the absorption of fatty acid. Microbiota can affect the increasing rate of host metabolism by modifying the production of bile salt and enhancing more fatty acid absorbed (Semova et al., 2012; Swann et al., 2011). These results are in accordance with the research conducted by Kasai et al. (2015), Riva et al. (2017) Ismail et al. (2010) Hou et al. (2017) Louis et al. (2016) and Andoh et al. (2016), in which the abundance of Bacteroidetes in obese individuals are lower, while Firmicutes and the $\mathrm{F} / \mathrm{B}$ ratio in obese individuals are higher than in non-obese individuals. The research conducted by Ley et al. (2006) also stated that Bacteroidetes and Firmicutes are the phyla that dominated the microbiota composition in obese individuals. Before the intervention of the weight loss diet program, Bacteroidetes composition is less and dominated by Firmicutes. But, after the administration of diet, the composition of Bacteroidetes increases and Firmicutes decreases.

The diversity in the microbiota composition is also found to be significantly higher in obese individuals. The bacteria Blautia hydrogenotorophica, Coprococcus catus, Eubacterium ventriosum, Ruminococcus bromii, and Ruminococcus obeum are part of the phylum Firmicutes which is significantly associated with the obesity incidence. Those bacteria can degrade starch or polysaccharides, and other non-digestible dietary nutrient sources, such as pectin and cellulose. These nutrients will be fermented and the result is the production of short-chain fatty acids (SCFAs), mainly butyrate, propionate, and acetate, which can be used to produce more energy than Bacteroidetes (Turnbaugh et al., 2006). SCFAs contribute approximately $200 \mathrm{kcal}$ per day (Krebs et al., 2002). The elevation level of SCFAs can both be protective and be the risk factor of obesity. The phylum Bacteroidetes dominantly produces acetate and propionate, whereas the phylum 
Firmicutes produce butyrate. Butyrate is used as an energy source for colonic epithelium, insulin sensitivity in mice, anti-inflammatory in humans, colon carcinoma protection, gene-expression of leptin, and protection against diet-induced obesity. Acetate contributes to gluconeogenesis, as well as propionate. Also, higher fecal SCFA concentrations may reflect a protective mechanism against obesity (Graham et al., 2015).

Moreover, these bacteria also carry genes in terms of enzymes such as CAZymes (carbohydrateactive enzymes) that play a role in the metabolism of polysaccharides, so that they can increase the efficiency of the energy production (Cantarel et al., 2012). A high abundance of Firmicutes is associated with an increase in energy extraction, which escalates the amount of energy intake (Beh et al., 2016). In non-obese individuals, specific bacterial species are included in the phylum Bacteroidetes, such as Bacteroides faecichinchillae, Bacteroides thetaiotaomicron, Blautia wexlerae, Clostridium bolteae, and Flavonifractor plautii, in which these bacteria are not found in obese individuals which can also be used as a decrease marker of metabolic syndrome (Kasai et al., 2015; Upadhyaya et al., 2016). However, Bacteroidetes are also linked with reduced body mass (De Filippo et al., 2010).

The concentrations of fecal SCFAs tend to increase in obese individuals (Schwiertz et al., 2010; Teixeira et al., 2013). This occurs because of the decrease in the SCFA absorption in the colon. The concentrations of fecal SCFAs are used as a determinant of the balance between production and absorption of SCFA in the colon (Vogt et al., 2003). Colonic fermentation is a process which requires the interaction between microbes and involves the degradation of nutrients, such as complex carbohydrate, dietary fiber, and protein through an anaerobic pathway (Macfarlane et al., 1990; Cummings et al., 1983; Smith et al., 1979). The final results of the process are SCFAs, including acetate, propionate, butyrate, hydrogen, carbon dioxide, methane, and energy (Topping et al., 2001; Cummings et al., 1981; Miller et al., 1979; Cummings et al., 1991). These final products are required for gut microbiota to carry out cellular function. SCFA concentrations are produced as much as $5-10 \%$ of total energy intake and may modulate body weight and obesity (Kasai et al., 2015). The greater the efficiency of energy extraction from microbiota, the higher the risk of obesity in an individual. The research conducted by Fernandes et al. (2018) showed that the number of Bacteroidetes was inversely associated to BMI; meanwhile, there was a positive association between the F/B ratio and SCFA concentrations; also, there was a negative association between the abundance of Bacteroidetes and SCFA concentrations. According to Turnbaugh et al. (2006), the difference in the higher $\mathrm{F} / \mathrm{B}$ ratio was associated with the elevated energy production from the colonic fermentation and caused the increase of SCFA production.

SCFAs have various roles; one of them is to take part in fat and glucose metabolism (Blaut \& Clavel, 2007; Lin et al., 2012). SCFA is a ligand for 2-paired receptors, GPR41 and GPR43, in which both receptors have different affinities. The GPR41 receptors have the highest affinity for propionic, butyric, and acetic acids, while the GPR43 receptors have the same affinity for the three acids. The bond of SCFAs, especially the bond of propionic acid and GPR41 receptors, will increase the expression of leptin, while the bond between acetic acid and GPR43 receptors will increase the secretion of leptin in the fat tissue (Backhed et al., 2004; Arora et al., 2011; Nie et al., 2018). SCFAs can be an effective strategy in preventing weight gain which can be inhibited by supplementation of acetate, propionate, and butyrate. The study by Degen et al. (2005) showed that SCFAs could become the factor to affect lipogenesis and could assist in the secretion of peptide YY (PYY), which plays a role in the regulation of appetite and food intake. Moreover, SCFA supplementation can affect the gut microbiota composition in the feces by reducing the number of Firmicutes and increasing the number of Bacteroidetes (Spiller et al., 1980).

The research conducted by Ismail et al. (2010) stated that gut microbiota contributed to the obesity process. The study results found that the high sensitivity C-reactive protein (hs-CRP) increased in obese individuals. This can occur since the increase in C-reactive protein level was caused by the high levels of interleukin-6 (IL6) in the adipose tissue and the release of IL- 6 into the peripheral blood circulation (Cani et al., 2008). Gut 
Table 1. Association between Firmicutes/Bacteroidetes Ratio with Obesity Problem

\begin{tabular}{c}
\hline Research Title and Author \\
\hline Association between body \\
mass index and Firmicutes/ \\
Bacteroidetes ratio in an adult \\
Ukrainian population (Koliada \\
et al., 2017)
\end{tabular}

Frequency of Firmicutes and Bacteroidetes in gut microbiota in obese and normal weight Egyptian children and adults (Ismail et al., 2011)

\section{Comparison of the gut} microbiota composition between obese and non-obese individuals in a Japanese population, as analyzed by terminal restriction fragment length polymorphism and next-generation sequencing (Kasai et al., 2015)

Adiposity, gut microbiota, and faecal short chain fatty acids are linked in adult human (Fernandes et al., 2014)

Human gut microbiota associated with obesity in Chinese children and adolescents (Hou et al., 2017)

Characterization of the gut microbial community of obese patients following a weight loss intervention using whole metagenome shotgun sequencing (Louis et al., 2016)

Comparison of the gut microbial 10 obese subjects and community between obese and lean peoples using $16 \mathrm{~s}$ gene sequencing in a Japanese population (Andoh et al., 2016)

Bacterial microbiota and fatty acids in the faeces of overweight and obese children (Barczynska et al., 2018)

Pediatric obesity is associated with an altered gut microbiota and discordant shifts in

Firmicutes population (Riva et al., 2017)

Differences in gut microbiota composition between obese and lean children: a cross-sectional study (Bervoets et al., 2013)
79 subjects, with 51 obese individuals and 28 individuals of normal weight.

56 subjects, 23 obese subjects and 33 subjects of normal weight.

94 subjects divided to 52 lean subjects (LN) and 42 overweight and obese subjects (OWOB).

87 obese children and 56 non obese children in age of 3-18 years old.

16 subjects joined in the weight loss program.

10 lean subjects.

20 obese children and

20 children of normal weight.

36 children of normal weight and 42 obese children in age of 6-16 years old.

26 overweight children and 27 lean children in age of 6-16 years old.
Design: cross sectional.

Analysis: DNA fecal samples were extracted and analyzed using qPCR using primers Firmicutes, Actinobacteria, and Bacteroidetes bacteria.

Design: cross sectional. Analysis: Fecal samples were collected. Total DNA was extracted from collected stool samples and analyzed using $\mathrm{qPCR}$ with primer Firmicutes and Bacteroidetes bacteria.

Design: cross sectional. Analysis: Fecal samples were collected. Gut microbiota were evaluated using T-RFLP analysis. Microbiota diversity was counted using Shannon-Weiner diversity index ( $\left.\mathrm{H}^{\prime}\right)$ for pylotypes number (richness and evenness)

Design: cross sectional Analysis: extract of fecal bacterial DNA was analyzed by RT PCR using primers of bacteria $C$. occoides and $C$. leptum

Design: cohort 90 days Analysis: extract of fecal bacterial DNA was analyzed by PCR, taxonomic analysis (OTU and QIME), and metagenomic.

Design: cross sectional. Analysis: extract of fecal bacterial DNA was analyzed using taxonomic analysis and metagenomic using

DNA shotgun sequencing.

Design: cross sectional. Analysis: extract of fecal bacterial DNA was analyzed by 16 s rRNA sequence using Illumina MiSeq II system.

Design: case control. Analysis: extract of fecal bacterial DNA was analyzed by RFLP and DNA sequencing.

Design: cohort.

Analysis: extract of fecal bacterial DNA was analyzed by DNA sequencing.

Design: cross sectional.

Analysis: extract of fecal bacterial DNA was analyzed by qPCR using primers of Bacteroides, Bifidobacterium, Clostridium, Lactobacillus, and Staphylococcus.

\author{
Result \\ Firmicutes increased and \\ Bacteroidetes decrease with increasing \\ BMI. F/B ratio also increased with \\ increasing $\mathrm{BMI}(\mathrm{OR}=1.23)$.
}

The proportions of Firmicutes and Bacteroidetes increased in obese group $(\mathrm{p}<0.001)$. There was a significant positive trend for hsCRP in subjects with higher levels of Firmicutes $(\mathrm{p}=0.004)$.

T-RFLP showed a significant reduction of Bacteroidetes and an increase of $\mathrm{F} / \mathrm{B}$ ratio on obese individuals compared to non-obese $(\mathrm{p}<0.05)$. Gut microbiota diversity on obese individuals was significantly greater.

Overweight and obese subjects had higher total SCFA $(p=0.002)$ than lean subjects. F/B ratio was shown to be positively correlated with total SCFA $(r=0.42 ; p<0.0001)$.

$\mathrm{F} / \mathrm{B}$ ratio in obese subjects was higher than in non-obese subjects.

$\mathrm{F} / \mathrm{B}$ ratio was higher in obese subjects with metabolic syndrome (0.64) than in healthy obese subjects $(0.27)$.

The number of Firmicutes was higher in obese group $(p<0.01)$. The number of Bacteroidetes and $\mathrm{F} / \mathrm{B}$ ratio are not significantly different in both groups.

Firmicutes dominated the fecal bacteria kind in obese children, whereas Bacteroidetes became minority $(\mathrm{p}<0.001)$. The number of SCFA was lower in obese children.

Obesity was correlated with the elevation of Firmicutes and the reduction of Bacteroidetes.

Obese children showed an increase of $\mathrm{F} / \mathrm{B}$ ratio. The proportion of B. vulgatus was much lower and Lactobacillus was higher. Lactobacillus in obese children had positive correlation with hsCRP. 
microbiota has a role in handling the inflammation condition by regulating lipopolysaccharide (LPS) concentration which triggers inflammation and the onset of obesity. This result is also shown in the study by Cani et al. (2007). The subcutaneous infusion of LPS can cause weight gain and insulin resistance in mice without changing the energy intake. The research conducted by Bervoets et al. (2013) also stated that Lactobacillus spp. was associated with hs-CRP levels in children and obese adults, so that the role of Lactobacillus spp. could affect the decrease of the inflammatory process in the obesity problem.

\section{The Role of Dietary Factors in the Balance of Firmicutes and Bacteroidetes Ratio}

Nutrients and bioactive compounds can be one of the factors which can influence the gut microbiota composition. Specific nutrients such as dietary fiber and amino acid have significant roles in the balance of gut microbiota. Moreover, the gut microbiota balance can also be affected by both prebiotics, probiotics, and polyphenol compounds found in food (Kishimoto et al., 2007; Flint et al., 2012).

\section{Fiber}

Obesity is caused by an energy imbalance between energy intake and expenditure. Soluble dietary fiber can promote energy balance (Brown et al., 1999; Chandalia et al., 2000; De Vadder et al., 2014). The research conducted by Wang et al. (2018) showed that obese mice given dietary fiber intake for 9 weeks had reduced weight gain. Dietary fiber intake can help to reduce fat mass and the size of adipose tissue, as well as to increase energy. This study found that soluble dietary fiber intake increased the energy expenditure through the experiment from mice induced by high-fat diet and fiber resulted in the elevation of energy expenditure. The change in gut microbiota composition such as the decrease of $\mathrm{F} / \mathrm{B}$ ratio can be associated with the weight loss induced by dietary fiber intake. The number and type of fiber are calculated based on gut microbiota composition and SCFA production (Macfarlane et al., 1995; Royall et al., 1990). The obesity protection mechanism from the dietary fiber is through the SCFA regulation which will secrete gut hormone peptide YY (PYY) in the intestine to help in regulating food intake and processing energy balance (Freeland et al., 2010; Tarini et al., 2010; Samuel et al., 2008). Table 1 explains that an increase in the abundance of Firmicutes and an increase in the $\mathrm{F} / \mathrm{B}$ ratio are closely correlated with the obesity problem, whereas an increase in Bacteroidetes is correlated with weight loss. Obese mice given a high dietary fiber intake showed an increase in the number of Bacteroidetes. Changes in the composition of this microbiota are correlated with weight loss, which becomes the effect of soluble dietary fiber intake.

Intervention research was also conducted by Dong et al. (2016) to compare the effects of three oat products, including oatmeal $(\mathrm{OM})$, oat flour (OF), and high-fiber oat bran (OB) on lipid metabolism and intestinal microbiota structure in obese mice. Oat products are known to be able to reduce body weight and reduce the LDL serum level. This can occur because of the role of $\beta$-glucan, which is one of the non-starch polysaccharides types. The $\beta$-glucan compound can increase the abundance of Lactobacillus and Bifidobacterium, and also can reduce the number of pathogenic bacteria such as Enterobacter. The analysis using PCA showed that oat products can change the structure and composition of the microbiota as a whole. Mice given all three oat products had the low F/B ratio and lower Firmicutes compared to obese mice given only a diet. Total fiber, $\beta$-glucan, and starch in $\mathrm{OB}$ products $(9.87 \%)$ did not undergo the metabolism in the small intestine and went through the fermentation process in the intestine, thereby maximizing the modification of gut microbiota composition and SCFA production, inhibiting weight gain and fat accumulation, as well as improving serum lipid and inflammation process (Nielsen et al., 2015).

Fiber and flavonoid sources from fruits and vegetables can assist in reducing the abundance of Firmicutes and elevating the abundance of Bacteroidetes. Fruits and vegetables contain bioactive compounds that can improve health status and reduce the risk of disease, as well as regulate the gut microbiota composition. Phenolic compounds and fiber are most commonly found in fruits and vegetables. Administration of fruit 
and vegetable juice is correlated with a decreased proportion of Firmicutes and an increasing proportion of Bacteroidetes (Henning, 2017). Carbohydrate complex supplementation, as in the type of pectin, which comes from apples is known to promote normalizing the level of Bacteroidetes and Firmicutes in high fat diet-induced mice. Pectin supplementation also lowers the level of endotoxin and reduces the inflammatory factors, such as TNF- $\alpha$ and IL-6 (Jiang et al., 2016). Dietary fiber intake from whole grains can also influence the reduction of Firmicutes as well as the elevation of Bacteroidetes and Lactobacillus, which can also lower the risk of inflammation (Vitaglone et al., 2015).

\section{Polyphenol Compounds}

Anthocyanin is one of the flavonoids that can regulate the microbiota composition and the gastrointestinal system. Jamar et al. (2017) stated that anthocyanin had an anti-obesity effect related to microbiota regulation. The research conducted by Hester et al. (2018) provided the intervention of anthocyanin and prebiotic fiber blend supplementation. After 8 weeks of intervention, it was found that there was a decrease in the number of Firmicutes, Actinobacteria, and F/B ratio, and a significant increase in the number of Bacteroidetes. The limitation of this study is that there was still no clear evidence and description of the role of specific bioactive compounds which influenced the most on the changes of gut microbiota composition.

Fermented food also has an anti-obesity effect, through changes in microbiota composition and gene expression associated with the metabolic syndrome process. The research conducted by Han et al. (2015) showed that subjects who consumed kimchi (fermented vegetables) experienced a decrease in the F/B ratio. Moreover, consumption of fermented products such as vinegar, which mostly contain acetic acid and other bioactive compounds, can protect and prevent hypertension, hypercholesterolemia, hyperglycemia, antimicrobial, and anticancer (Mohamad et al., 2015). The research conducted by Beh et al. (2017) also showed the intervention of synthetic acetic acid vinegar and Nipa vinegar can significantly reduce the F/B ratio and increase Bacteroidetes,
Lactobacillus, Parabacteroides, Akkermansia, Proteobacteria, and Oscillospira. Firmicutes were able to ferment unabsorbed nutrients, namely fermented food, in the gut and increased Bacteroidetes in the gut (Beh et al., 2016). Both synthetic acetic acid vinegar and Nipa vinegar were able to reduce the food intake of obese mice and alter the gut microbiota composition, which contributed to weight loss. In this study, fermented Nipa vinegar was considered superior to synthetic acetic acid vinegar in its benefits for weight loss, the hyperlipidemia effect, and the hepatoprotective effect due to the presence of phenolic metabolites, namely gallic acid and protocatric acid. These phenolic compounds are correlated with antiinflammatory effects and can assist in restoring oxidative stress caused by obesity and liver inflammation.

\section{Amino Acid}

The administration of amino acid glutamine based on de Souza et al. (2015) can reduce the $\mathrm{F} / \mathrm{B}$ ratio, with a decrease in the number of Firmicutes and an increase in Bacteroidetes. This study showed that the effects of glutamine supplementation on gut microbiota composition were similar to individuals who experienced weight loss. However, this study did not show a significant difference in the number of Bacteroidetes in the groups given alanine and glutamine, since both groups experienced a decrease in the number of Bacteroidetes. The group given glutamine experienced a decreased number of Firmicutes more than another. The administration of glutamine supplementation can also reduce inflammatory factors, such as TNF- $\alpha$ and IL-6 in serum and peripheral tissue (Greenfield et al., 2013; Prada et al., 2007). In this study, the amount of Veillonella decreased after glutamine supplementation, which also became a marker for inflammation (De Filippo et al., 2010).

\section{Prebiotics}

Prebiotics are beneficial for the regulation of the gut microbiota composition and metabolism (Roberfroid, 2007; Parnell, 2012; Delzenne, 2003). Prebiotics are known to be able to alter the Firmicutes and Bacteroidetes composition (Okazaki et al., 2016). Prebiotics compound from 
Table 2. The Role of Dietary Factors in Modifying Firmicutes/Bacteroidetes Ratio

\begin{tabular}{|c|c|}
\hline Research Title and Author & Subjects \\
\hline $\begin{array}{l}\text { Soluble dietary fiber improves } \\
\text { energy homeostasis in obese mice } \\
\text { by remodeling the gut microbiota } \\
\text { (Wang et al., 2018) }\end{array}$ & $\begin{array}{l}\text { WT (wild type) } \\
\text { mice was fed with } \\
\text { high fat diet until it } \\
\text { reached obesity. }\end{array}$ \\
\hline $\begin{array}{l}\text { Anti- obesity and anti- inflammatory } \\
\text { effects of synthetic acetic acid } \\
\text { vinegar and Nipa vinegar on high- } \\
\text { fat- diet- induced obese mice (Beh } \\
\text { et al., 2017) }\end{array}$ & $\begin{array}{l}36 \text { C57BL/6 mice } \\
\text { were fed with } \\
\text { high fat diet for } 33 \\
\text { weeks. }\end{array}$ \\
\hline $\begin{array}{l}\text { Oat products modulate the gut } \\
\text { microbiota and produce anti-obesity } \\
\text { effects in obese rats (Dong et al., } \\
2016)\end{array}$ & $\begin{array}{l}80 \text { SD (Spraguw- } \\
\text { Dawley) mice were } \\
\text { fed with high fat } \\
\text { diet for } 6 \text { weeks. }\end{array}$ \\
\hline $\begin{array}{c}\text { Efficacy of an anthocyanin and } \\
\text { prebiotic blend on intestinal } \\
\text { environment in obese male and } \\
\text { female subjects (Hester et al., 2018) }\end{array}$ & $\begin{array}{c}\text { Subjects aged } 18- \\
50 \text { years old with } \\
\text { BMI } 29.9-39.9 \\
\mathrm{~kg} / \mathrm{m}^{2}\end{array}$ \\
\hline
\end{tabular}

Oral supplementation with L-glutamine alters gut microbiota of obese and overweight adults: a pilot study (deSouza et al., 2015)
33 overweight and obese subjects, aged 23-59 years old.
Design: RCT intervention 2\% of soluble dietary fiber.

Analysis: extract of fecal bacterial DNA was collected to determine gut microbiota using 16s rRNA sequencing using Illumina MiSeq platform.

Design: RCT intervention with synthetic acetic acid vinegar and Nipa vinegar.

Analysis: extract of fecal bacterial DNA was used to analyze by using 16s rRNA metagenomic sequencing.

Design: RCT intervention with oat meal (OM), oat flour (OF), and high fiber oat bran (OB).

Analysis: extract of fecal bacterial DNA was analyzed by PCR and phylogenetic.

Design: RCT intervention with supplementation of $215 \mathrm{mg}$ extract of anthocyanin and 2.7 gram prebiotic fiber (inulin from FOS). Analysis: extract of fecal bacterial

DNA was analyzed by sequence analysis and taxonomic.

Design: RCT intervention with supplementation of 30 gram

L-alanine or 30 gram L glutamine for 14 weeks.

Analysis: extract of fecal bacterial DNA was analyzed by newgeneration sequencing.

SD mice aged 4 Design: RCT intervention with 7\% weeks old were fed $\quad$ RLB, $7 \%$ SLB, $0.9 \%$ extract of with high fat diet. ethanol, or $6.1 \%$ extract of ethanol LB residue. fecal ratios of Firmicutes and Bacteroidetes phyla in rats fed a high-fat diet (Okazaki et al., 2016)

Health benefit of vegetable/fruit juice-based diet: role of microbiome (Henning et al., 2017)

Whole-grain wheat consumption reduces inflammation in a randomized controlled trial on overweight and obese subjects with unhealthy dietary and lifestyle behaviors: role of polyphenols bound to cereal dietary fiber (Vitaglione et al., 2015)

\section{5 healthy adolescents, aged 18-50 years old.}

80 overweight/ obese subjects with low intake of fruits and vegetables and sedentary lifestyle.
DNA was analyzed by qPCR.

Design: RCT intervention for 3 days of fruit/vegetables juice.

Analysis: extract of fecal bacterial

DNA was analyzed by sequence analysis and taxonomic.

Design: RCT intervention with whole grain wheat (WG) or refined wheat (RW) for 8 weeks.

Analysis: extract of fecal bacterial DNA was analyzed by PCR sequence and taxonomic (QIME and OTU).

Result

Soluble dietary fiber lowered the number of Firmicutes and increased the number of Bacteroidetes, so that $\mathrm{F} / \mathrm{B}$ was decreased in obese mice.

Synthetic acetic acid vinegar and Nipa vinegar lowered the $\mathrm{F} / \mathrm{B}$ ratio. A significant increase of Bacteroides,

Lactobacillus, Akkermansia, Parabacteroides, and Proteobacteria $(\mathrm{p}<0.05)$.

Three oat products altered the structure of gut microbiota, especially an increase of

Bacteroidetes, a decrease of Firmicutes, and $\mathrm{F} / \mathrm{B}$ ratio $(\mathrm{p}<0.05)$.

There was a significant decrease of Firmicutes $(74.9 \%$ to $59 \%$ ), Actinobacteria, $\mathrm{F} / \mathrm{B}$ ratio (14.2\% to $9.3 \%)$, and also an increase of Bacteroidetes (13.8\% to $34.5 \%)(\mathrm{p}<0.001)$.

Group administered with L-glutamine showed a significant decrease $\mathrm{F} / \mathrm{B}$ ratio (0.85 to 0.57 ), whereas the group administered with

L-alanine showed a significant increase of $\mathrm{F} / \mathrm{B}$ ratio ( 0.91 to 1.12).

There was a decrease of Firmicutes and an increase of Bacteoideters in RLB and SLB groups. F/B ratio was not much influenced by ethanol extract or LB residual extract.

There was a decrease of Firmicutes and Proteobacteria proportion. There was an increase of Bacteroidetes and Cyanobacteria.

Whole grain consumption increased Bacteroidetes and Firmicutes but decreased Clostridium. There was an increase of DHFA (4 times) and fecal ferulic acid. There was a decrease of TNF- $\alpha$ and an increase of IL-10. 


\begin{tabular}{|c|c|c|c|}
\hline Research Title and Author & Subjects & Method & Result \\
\hline $\begin{array}{l}\text { Reinforcement of intestinal } \\
\text { epithelial barrier by arabinoxylans } \\
\text { in overweight and obese subjects: } \\
\text { a randomized controlled trial } \\
\text { arabinoxylans in gut barrier (Salden } \\
\text { et al., 2018) }\end{array}$ & $\begin{array}{l}47 \text { overweight/ } \\
\text { obese subjects aged } \\
18-70 \text { years old, } \\
\text { BMI } 28-35 \mathrm{~kg} / \mathrm{m}^{2}\end{array}$ & $\begin{array}{c}\text { Design: RCT intervention } 7.9 \\
\text { gram/day of arabinoxylans (AX) } \\
\text { and } 15 \text { gram/day of AX. } \\
\text { Analysis: extract of fecal bacterial } \\
\text { DNA was analyzed by 16s rRNA } \\
\text { sequencing using Illumina MiSeq } \\
\text { platform. }\end{array}$ & $\begin{array}{l}\text { There was no significant } \\
\text { differences in the number of } \\
\text { Firmicutes and Bacteroidetes } \\
\text { in six weeks. But, there was a } \\
\text { decrease in diversity, fecal pH, } \\
\text { and an increase in total SCFA. }\end{array}$ \\
\hline $\begin{array}{l}\text { Combined effects of oligofructose } \\
\text { and Bifidobacterium animalis on gut } \\
\text { microbiota and glycemia in obese } \\
\text { rats (Bomhof et al., 2014) }\end{array}$ & $\begin{array}{l}\text { Adult male SD } \\
\text { mice were fed with } \\
\text { high fat diet. }\end{array}$ & $\begin{array}{l}\text { Design: RCT intervention with } \\
10 \% \text { OFS, } B \text {. animalis sub lactis } \\
\text { BB-12, and the combination of } \\
\text { both for } 8 \text { weeks. } \\
\text { Analysis: extract of fecal bacterial } \\
\text { DNA was analyzed by qPCR. }\end{array}$ & $\begin{array}{c}\text { F/B ratio decreased after } \\
\text { administration of prebiotic } \\
(\mathrm{p}=0.0015) \text { and probiotic } \\
(\mathrm{p}=0.0011) . \text { Prebiotics are able } \\
\text { to lower the energy intake, } \\
\text { increase body weight, and fat } \\
\text { mass. }\end{array}$ \\
\hline $\begin{array}{c}\text { Yellow pea fiber improves glycemia } \\
\text { and reduces Clostridium leptum in } \\
\text { diet- induced obese rats (Eslinger et } \\
\text { al., 2014) }\end{array}$ & $\begin{array}{l}\text { Adult male SD } \\
\text { mice were fed with } \\
\text { high fat diet and } \\
\text { sucrose. }\end{array}$ & $\begin{array}{l}\text { Design: RCT intervention with } \\
\text { oligofructose (OFS), yellow pea } \\
\text { fiber (PF), yellow pea starch (PS), } \\
\text { and yellow pea flour (PFL). } \\
\text { Analysis: extract of fecal bacterial } \\
\text { DNA was analyzed by qPCR. }\end{array}$ & $\begin{array}{l}\text { Firmicutes and F/B ratio } \\
\text { decreased in OFS, PF, and } \\
\text { PFL groups. Pea fiber can } \\
\text { lower the fasting blood } \\
\text { glucose and the area under } \\
\text { glucose curve. }\end{array}$ \\
\hline $\begin{array}{l}\text { Apple-derived pectin modulates gut } \\
\text { microbiota, improves gut barrier } \\
\text { function, and attenuates metabolic } \\
\text { endotoxemia in rats with diet- } \\
\text { induced obesity (Jiang et al., 2016) }\end{array}$ & $\begin{array}{l}\text { Adult male SD } \\
\text { mice were fed with } \\
\text { high fat diet. }\end{array}$ & $\begin{array}{l}\text { Design: RCT intervention } \\
\text { with apple-derived pectin } \\
\text { supplementation for } 6 \text { weeks. } \\
\text { Analysis: extract of fecal bacterial } \\
\text { DNA was analyzed by qPCR. }\end{array}$ & $\begin{array}{c}\text { Administration of pectin } \\
\text { can restore the abundance of } \\
\text { Bacteroidetes and Firmicutes } \\
\text { after high-fat diet induced. } \\
\text { Moreover, it can also reduce } \\
\text { inflammation and metabolic } \\
\text { endotoxemia. }\end{array}$ \\
\hline
\end{tabular}

lily bulbs (Lilium leichtlinii var. maximowiczii Baker) proves to be able to reduce the proportion of $\mathrm{F} / \mathrm{B}$ ratio. Moreover, prebiotics and fiber contained in pea fiber (PF) and pea flour (PFL) can also alter the gut microbiota composition by reducing the Firmicutes level, namely C. leptum (Eslinger et al., 2014), which usually increases in obese individuals (Angelakis et al., 2012). Oligofructose is known to be able to elevate the abundance of Bifidobacteria which plays a role in intestinal health (Russell et al., 2011). The research about oligofructose, prebiotics, and probiotics conducted by Bomhof et al. (2014) showed that oligofructose could increase the abundance of Bifidobacterium spp. and Lactobacillus spp.

Supplementation of lactic acid bacteria, such as L. plantarum, affects the reduction of adipose tissue accumulation and the changes in the gut microbiota (Park et al., 2016). Despite not providing specific effect, the combination of probiotics and prebiotics are known to be able to decrease the $\mathrm{F} / \mathrm{B}$ ratio. The decrease in this ratio is caused by the increasing number of Bacteroides spp. (Bomhof et al., 2014). The prebiotic limitation is the rapid fermentation process in the proximal colon. One of the prebiotics which can be fermented in stages is arabinoxylan (AX) since the structure relies on the enzyme spectrum. The effects of AX to the microbiota composition require six weeks, marked with the elevated levels of fecal SCFAs and the reduction of fecal $\mathrm{pH}$ (Grootaert et al., 2009; Hughes et al., 2007).

Studies of gut microbiota in the human gastrointestinal tract require invasive sampling methods that cannot be scaled for practical and ethical considerations. This is the reason why mice are often used as a better alternative for similar research. Mice have become the most studied models for microbial diversity in the gastrointestinal tract. The difference in the gastrointestinal tract between humans and mice, particularly in the tract size and dietary habits, can be the factors that differentiate the total size of the species in the gastrointestinal tract (Ley et al., 2006; Rawls et al., 2006). Nevertheless, the phylogenetic makeup of the microbiota composition in both humans and mice seems to share similarity at the phylum level, with 
Firmicutes and Bacteroidetes as the two main bacterial phyla. Though the microbiota looks alike but the quantitative abundance is different (Krych et al., 2013). This should be carefully considered during experimental design and interpretation.

To the best of our knowledge, this review was the first to attempt to discuss and elaborate on the effect of dietary factors in gut microbiota composition, especially in the Firmicutes and Bacteroidetes ratio.

The research articles in this review used standardized methods which could attribute to the accurate results. Though, most of the reviewed articles showed that there was a decrease in Firmicutes and an increase in Bacteroidetes in the effect of the dietary factors, yet the mechanisms of lowering the $\mathrm{F} / \mathrm{B}$ ratio through the nutrients and bioactive compounds are still unclear. Future studies are required to discuss these mechanisms further. There were limitations from the research articles we reviewed, such as the studies did not observe and analyze further the modulation of dietary fiber on the gut microbiota composition; metagenomics method should be used to analyze and determine the gut microbiota composition; the unblended participants in data collection could be a possible factor for biases in psychological responses; and, there was a study conclusion that did not separate the gut microbiota in rats and humans which could not be attributed to translate the similar thing in humans. It is required to carry out clinical trials to address the benefits of applederived pectin in humans.

Also, there were several limitations to this review. This review did not separate the role and influence of dietary factors in human and animal studies and did not separate the obese and overweight subjects.

\section{CONCLUSIONS}

The composition and ratio of the two microbiotas can be influenced by several factors, and one of them is nutrient dietary intake. Several nutrients, such as fiber, organic acid, polyphenol, and fat, can influence the alteration of the Firmicutes and Bacteroidetes composition. One of the ways suggested to reduce the number of obesity problems is by increasing the diet enriched with fiber, polyphenol compounds, organic acid, fruits, and vegetables to make a better Firmicutes and Bacteroidetes composition.

\section{REFERENCES}

Andoh, A., Nishida, A., Takahashi, K., Inatomi, O., Imaeda, H., Bamba, S., ... Kobayashi, T. (2016). Comparison of the gut microbial community between obese and lean peoples using $16 \mathrm{~S}$ gene sequencing in a Japanese population. Journal of Clinical Biochemistry Nutrition, 59(1), 65-70. Retrieved from: https://www.ncbi.nlm.nih.gov/ pmc/articles/PMC4933688/

Angelakis, E., Armougom, F., Million, M., \& Raoult, D. (2012). The relationship between gut microbiota and weight gain in humans. Future Microbiology, 7(91), 109. Retrieved from: https://www.futuremedicine.com/doi/ pdfplus/10.2217/fmb.11.142

Apovian, C. M. (2016). The obesity epidemicunderstanding the disease and the treatment. New England Journal of Medicine, 374:177179. Retrieved from: https://www.nejm.org/ doi/10.1056/NEJMe1514957?url_ver=Z39.882003\&rfr_id=ori\%3Arid\%3Acrossref.org\&rfr_ dat $=$ cr_pub\%3Dwww.ncbi.nlm.nih.gov

Arora, T., Sharma, R., \& Frost, G. (2011). Propionate. Anti-obesity and satiety factor? Appetite, 56(2), 511-515. Retrieved from: https://www.sciencedirect.com/science/article/ pii/S0195666311000328?via\%3Dihub

Backhed, F., Ding, H., Wang, T., Hooper, L. V., Koh, G. Y., Nagy, A., ... Gordon, J. I. (2004). The gut microbiota as an environmental factor that regulates fat storage. Proceedings of the National Academy of Sciences of the United States of America, 101(4), 15718-15723. Retrieved from: https://www.ncbi.nlm.nih.gov/ pmc/articles/PMC524219/

Barczynska, R., Litwim, M., Slizewska, K., Berdowska, A., Bandurska, K., Libudzisz, Z., \& Kapusniak, J. (2018). Bacterial microbiota and fatty acids in the faeces of overweight and obese children. Polish Journal of Microbiology, 67(3), 339-345. Retrieved from: https://www. ncbi.nlm.nih.gov/pubmed/30451451

Beh, B. K., Mohamad, N. E., Yeap, S. K., Lim, K. L., Ho, W. Y., Yusof, H. M., ... Alitheen, N.B. (2016). Polyphenolic profiles and the in vivo antioxidant effect of nipa vinegar on paracetamol induced liver damage. Royal Society of Chemistry Advance, 68, 63304-63313. Retrieved from: https://pubs. 
rsc.org/en/content/articlelanding/2016/ra/ c6ra13409b\#!divAbstract

Beh, B. K., Mohamad, N. E., Yeap, S.K., Lim, K.L., Ho, W.Y., Yusof, H.M., ... Alitheen, N.B. (2017). Anti-obesity and anti-inflammatory effects of synthetic acetic acid vinegar and Nipa vinegar on high-fat-diet induced obese mice. Nature, 7(1), 1-9. Retrieved from: https://www. ncbi.nlm.nih.gov/pmc/articles/PMC5532206/

Boeverts, L., Hoorenbeeck, K. V., Kortleven, I., Noten, C. V., Hens, N., Vael, C., ... Vankerckhoven, V. (2013). Differences in gut microbiota composition between obese and lean children: a cross-sectional study. Gut Pathogens, 5(10). Retrieved from: https://www. ncbi.nlm.nih.gov/pmc/articles/PMC3658928/ pdf/1757-4749-5-10.pdf

Bomhof, M. R., Saha, D. C., Reid, D. T., Paul, H. A., \& Reimer, R. A. (2014). Combined effects of oligofructose and Bifidobacterium animalis on gut microbiota and glycemia in obese rats. Obesity (Silver Spring), 22(3), pp. 763-71. Retrieved from: https://onlinelibrary.wiley.com/ doi/full/10.1002/oby.20632

Brown, L., Rosner, B., Willett, W. W., \& Sacks, F. M. (1999). Cholesterol-lowering effects of dietary fiber: a meta-analysis. American Journal of Clinical Nutrition, 69(1), 30-42. Retrieved from: https://academic.oup.com/ajcn/ article/69/1/30/4694117

Cani, P. D., Amar, J., Iglesias, M. A., Poggi, M., Knauf, C., Bastelica, D., ... Burcelin, R. (2007). Metabolic endotoxemia initiates obesity and insulin resistance. Diabetes. 56(7), pp. 1761-1772. Retrieved from: http://diabetes. diabetesjournals.org/content/56/7/1761.long

Cani, P. D., Delzenne, N. M., Amar, J., \& Burcelin, R. (2008). Role of gut microflora in the development of obesity and insulin resistance following high-fat diet feeding. Pathologie Biologie, 56(5), 305-309. Retrieved from: https://www.sciencedirect.com/science/article/ pii/S0369811407002210?via\%3Dihub

Cani, P. D., Osto, M., Geurts, L., \& Everard, A. (2012). Involvement of gut microbiota in the development of low-grade inflammation and type 2 diabetes associated with obesity. Gut Microbes, 3(4), pp 279-288. Retrieved from: https://www.ncbi.nlm.nih.gov/pmc/articles/ PMC3463487/pdf/gmic-3-279.pdf

Cantarel, B. L., Lombard, V., \& Henrissat, B. (2012). Complex carbohydrate utilization by the healthy human microbiome. PLoS One, 7(6), e28742. Retrieved from: https://journals.plos. org/plosone/article/file?id=10.1371/journal. pone. $0028742 \&$ type $=$ printable

Chandalia, M., Garg, A., Lutjohann, D., von Bergmann, K., Grundy, S. M., \& Brinkley, L. J. (2000). Beneficial effects of high dietary fiber intake in patients with type 2 diabetes mellitus. New England Journal of Medicine, 342, pp. 1392-1398. Retrieved from: https://www.nejm. org/doi/pdf/10.1056/NEJM200005113421903

Chen, J., He, X., \& Huang, J. (2014). Diet effects in gut microbiome and obesity, Journal of Food Science, 79(4). Retrieved from: https:// onlinelibrary.wiley.com/doi/full/10.1111/17503841.12397

Cummings, J. H. (1981). Short chain fatty acids in the human colon. Gut, 22(9), 763-779. Retrieved from: https://www.ncbi.nlm.nih.gov/pmc/ articles/PMC1419865/

Cummings, J. H. (1983). Fermentation in the human large intestine: evidence and implications for health. Lancet, 1(8335), 1206-9. Retrieved from: https://www.ncbi.nlm.nih.gov/ pubmed $/ 6134000$

Cummings, J. H., \& Macfarlane, G. T. (1991). The control and consequences of bacterial fermentation in the human colon. Journal of Applied Bacteriology, 70(6), 443-459. Retrieved from: https://onlinelibrary.wiley.com/ doi/10.1111/j.1365-2672.1991.tb02739.x

Cummings. J. H., Rombeau, J. L., \& Sakata, T. (1995). Physiological and clinical aspects of short chain fatty acid metabolism. Cambridge University Press: Cambridge, 87-105.

David, L. A., Maurice, C. F., Carmody, R. N., Gootenberg, D. B., Button, J. E., Wolfe, B. E., ... Turnbaugh, P.J. (2014). Diet rapidly and reproducibly alters the human gut microbiome. Nature, 505(7484), 559-563. Retrieved from: https://www.ncbi.nlm.nih.gov/pmc/articles/ PMC3957428/

Davis, C. D. (2016). The gut microbiome and its role in obesity, Nutrition Today, 51(4), pp. 167-174. Retrieved from: https://www.ncbi. nlm.nih.gov/pmc/articles/PMC5082693/

Delzenne, N. M., 2003. Oligosaccharides: state of the art. Nutrition society, 62(1), 177-182. Retrieved from: https://www.cambridge.org/ core/services/aop-cambridge-core/content/vie w/68515DB878EB478FDF43B8522ED17CA F/S0029665103000272a.pdf/oligosaccharides state_of_the_art.pdf 
De Filippo, C., Cavalieri, D., Di Paola, M., Ramazzotti, M., Poullet, J. B., Massart, S., ... Lionetti, P. (2010). Impact of diet in shaping gut microbiota revealed by a comparative study in children from Europe and rural Africa. Proceedings of the National Academy of Sciences of the United States of America, . 107(33), 14691-14696. Retrieved from: https://www.ncbi.nlm.nih.gov/pmc/articles/ PMC2930426/

De Souza, A. Z., Zambom, A. Z., Abboud, K. Y., Reis, S.K., Tannihao, F., Guadagnini, D., ... Prada, P.O. (2015). Oral supplementation with L-glutamine alters gut microbiota of obese and overweight adults: A pilot study. Nutrition, 31(6), 884-889. Retrieved from: https:// www.sciencedirect.com/science/article/pii/ S0899900715000350?via\%3Dihub

De Vadder, F., Kovatcheva-Datchary, P., Goncalves, D., Vinera, J., Zitoun, C., Duchampt, A., ..., Mithieux, G., (2014). Microbiota-generated metabolites promote metabolic benefits via gut-brain neural circuits, Cell, 156(1), 84-96. Retrieved from: https://www.cell.com/action/ showPdf?pii=S0092-8674\%2813\%2901550-X

Degen, L., Oesch, S., \& Casanova, M., (2005). Effect of peptide YY 3-36 on food intake in humans. Gastroenterology, 129(5), 1430-1436. Retrieved from: https://www.gastrojournal. org/article/S0016-5085(05)01785-3/fulltext? referrer=https $\% 3 \mathrm{~A} \% 2 \mathrm{~F} \% 2 \mathrm{Fwww}$.ncbi.nlm. nih.gov\%2F

Dibner, J. J., \& Buttin, P. (2002). Use of organic acids as a model to study the impact of gut microflora on nutrition and metabolism. Journal of Applied Poultry Research, 11, 453-463. Retrieved from: https://pdfs.semanticscholar.org/6c7e/ bbc43ac338a6827faf3617de93262b040fd2. pdf

Dong, J., Zhu, Y., Ma, Y., Xiang, Q., Shen, R., \& Liu, Y. (2016). Oat products modulate the gut microbiota and produce anti-obesity effects in obese rats. Journal of Functional Foods, 205, 408-420. Retrieved from: https:// www.sciencedirect.com/science/article/pii/ S1756464616301682

Eslinger, A. J., Eller, L. K., \& Reimer, R. A. (2014). Yellow pea fiber improves glycemia and reduces Clostridium leptum in diet- induced obese rats. Nutrition Research, 34(8), pp. 714-22. Retrieved from: https://www.sciencedirect.com/science/ article/pii/S0271531714001237?via\%3Dihub
Flint, H. K., Scott, K. P., Louis, P., \& Duncan, S. H. (2012). The role of the gut microbiota in nutrition and health. Nature Reviews Gastroenterology and Hepatology, 9, 577589. Retrieved from: https://www.nature.com/ articles/nrgastro.2012.156

Gerber, J. (2014). Overweight and Obesity in Adults, UWS Clinics: Conservative Care Pathways.

Graf, D., Di Cagno, R., Fåk, F., Flint, H.J., Nyman, M., Saarela, M., \& Watzl, B. (2015). Contribution of diet to the composition of the human gut microbiota. Microbial Ecology in Health and Disease, 26. Retrieved from: https://www.ncbi.nlm.nih.gov/pmc/articles/ PMC4318938/

Graham, C., Mullen, A., \& Whelan, K. (2015). Obesity and the gastrointestinal microbiome: a review of associations and mechanisms. Nutrition Reviews, 73(6), 376-385. Retrieved from: https://academic.oup.com/nutritionreviews/ article/73/6/376/1845882

Greenfield, J. R., Farooqi, I. S., Keogh, J. M., Henning, E., Habib, A. M., Blackwood, A., ... Gribble, F.M. (2009). Oral glutamine increases circulating glucagon-like peptide 1, glucagon, and insulin concentrations in lean, obese, and type 2 diabetic subjects. American Journal of Clinical Nutrition, 89(1), 106-113. Retrieved from: https://www.ncbi.nlm.nih.gov/pme/ articles/PMC4340573/

Grootaert, C., Van den Abbeele, P., Marzorati, M., Broekaert, W. F., Courtin, C. M., Delcour, J. A., ... Van de Wiele, T., (2009). Comparison of prebiotic effects of arabinoxylan oligosaccharides and inulin in a simulator of the human intestinal microbial ecosystem. FEMS Microbiology Ecology, 69(2), 231-42. Retrieved from: https://academic.oup.com/ femsec/article/69/2/231/631072

Han, K. S., Bose, S., Wang, J. H., Kim, B. S., Kim, M. J., Kim, E. J., Kim, H. J., (2015). Contrasting effects of fresh and fermented kimchi consumption on gut microbiota composition and gene expression related to metabolic syndrome in obese Korean women. Molecular Nutrition and Food Research, 59(5), 1004-1008. Retrieved from: https://onlinelibrary.wiley.com/ doi/abs/10.1002/mnfr.201400780

Henning, S. M., Yang, J., Shao,P., Lee, R. P., Huang, J., Ly, A., ... Li, Z. (2017). Health benefit of vegetable/fruit juice-based diet: Role 
of microbiome. Nature, 7(1), 1-9. Retrieved from: https://www.nature.com/articles/s41598017-02200-6

Hester, S. N., Mastaloundis, A., Gray, R., Antony, J. M., Evans, M., \& Wood, S. M. (2018). Efficacy of an anthocyanin and prebiotic blend on intestinal environment in obese male and female subjects. Journal of Nutrition and Metabolism, 2018. Retrieved from: https://www.ncbi. nlm.nih.gov/pmc/articles/PMC6158948/pdf/ JNME2018-7497260.pdf

Hill, J. O., Wyatt, H. R., \& Peters, J. C. (2013). Energy Balance and Obesity. Circulation, 126(1), 126-132. Retrieved from: https://www. ncbi.nlm.nih.gov/pmc/articles/PMC3401553/

Hou, Y. P., He, Q. Q., Ouyang, H. M., Peng, H. S., Wang, Q., Li, J., ... Yin, A. H. (2017). Human gut microbiota associated with obesity in Chinese children and adolescents. BioMed Research International, 2017. Retrieved from: https://www.hindawi.com/journals/ bmri/2017/7585989/

Hughes, S. A., Shewry, P. R., Li, L., Gibson, G. R., Sanz, M. L., \& Rastall, A. A. (2007). In vitro fermentation by human fecal microflora of wheat arabinoxylans. Journal of Agricultural and Food Chemistry, 55(11), 4589-4595. Retrieved from: https://pubs.acs.org/doi/ pdf $/ 10.1021 / \mathrm{jf070293g}$

Ismail, N. A., Ragab, S. H., ElBaky, A. A., Shoeib, A. R. S., Alhosary, Y., \& Fekry, D. (2011). Frequency of Firmicutes and Bacteroidetes in gut microbiota in obese and normal weight Egyptian children and adults. Archives of Medical Science, 7(3), 501-507. Retrieved from: https://www.ncbi.nlm.nih.gov/pmc/articles/ PMC3258740/

Jamar, G., Estadella, D., \& Pisani, L. P. (2017). Contribution of anthocyanin-rich foods in obesity control through gut microbiota interactions, BioFactors, 43(4), 507-516. Retrieved from: https://iubmb.onlinelibrary.wiley.com/doi/ abs/10.1002/biof.1365

Jiang, T., Gao, X., Chao, W., Tian, F., Lei, Q., Bi, J., ..., Wang, X. (2016). Apple-derived pectin modulates gut microbiota, improves gut barrier function, and attenuates metabolic endotoxemia in rats with diet-induced obesity. Nutrients, 8(3), 126. Retrieved from: https://www.ncbi.nlm.nih. gov/pmc/articles/PMC4808856/pdf/nutrients08-00126.pdf

Kasai, C., Sugimoto, K., Moritani, I., Tanaka, J., Oya, Y., Inoue, H., ... Takase, K. (2015). Comparison of the gut microbiota composition between obese and non-obese individuals in a Japanese population, as analyzed by terminal restriction fragment length polymorphism and nextgeneration sequencing. BMC Gastroenterology, 15: 100. Retrieved from: https://www.ncbi.nlm. nih.gov/pmc/articles/PMC4531509/

Kishimoto, Y., Oga, H., Tagami, H., Okuma, K., \& Gordon, D.T. (2007). Suppressive effect of resistant maltodextrin on postprandial blood triacylglycerol elevation. European Journal of Nutrition, 46(3), 133-138. Retrieved from: https:// link.springer.com/article/10.1007\%2Fs00394007-0643-1

Krebs, M., Krssak, M., Bernroider, E., Anderwald, C., Brehm, A., Meyerspeer, M., ... Roden, M., (2002) Mechanism of amino acid-induced skeletal muscle insulin resistance in humans. Diabetes, 51(3), 599-605. Retrieved from: https:// diabetes.diabetesjournals.org/content/51/3/599. full-text.pdf

Krajmalnik-Brown, R., Ilhan, Z. E., Kang, D. W., $\&$ DiBaise, J. K. (2012). Effects of gut microbes on nutrient absorption and energy regulation. Nutrition in Clinical Practice, 27(2), 201-214. Retrieved from: https://www.ncbi.nlm.nih.gov/ pmc/articles/PMC3601187/\#

Krych, L., Hansen, C. H., Hansen, A. K., van den Berg, F. W., \& Nielsen, D. S. (2013). Quantitatively different, yet qualitatively alike: a meta-analysis of the mouse core gut microbiome with a view towards the human gut microbiome. PLoS One, 8(5), e62578. Retrieved from: https://www.ncbi.nlm.nih.gov/ pmc/articles/PMC3641060/

Koliada, A., Syzenko, G., Moseiko, V., Budovska, L., Puchkov, K., Perederiy, V., ... Vaiserman, A., (2017). Association between body mass index and Firmicutes/Bacteroidetes ratio in an adult Ukrainian population. BMC Microbiology, 17(1). Retrieved from: https://bmcmicrobiol. biomedcentral.com/articles/10.1186/s12866017-1027-1

Korem, T., Zeevi, D., Suez, J., Weinberger, A., Avnit-Sagi, T., Pompan-Lotan, M., ... Segal, E. (2015). Growth dynamics of gut microbiota in health and disease inferred from single metagenomic samples. Science, 349(6252), 1101-1106. Retrieved from: https://www.ncbi. nlm.nih.gov/pmc/articles/PMC5087275/pdf/ nihms-825065.pdf

Ley, R. E., Peterson, D. A., \& Gordon, J. I. (2006). Ecological and evolutionary forces shaping 
microbial diversity in the human intestine. Cell 124(4), 837-48. Retrieved from: https:// www.cell.com/action/showPdf?pii=S00928674\%2806\%2900192-9

Ley, R. E., Turnbaugh, P. J., Klein, S., \& Gordon, J.I. (2006). Microbial ecology: human gut microbes associated with obesity. Nature, 444(7122), 1022-1023. Retrieved from: https:// www.researchgate.net/publication/6617713 Microbial_Ecology_Human_gut_microbes_ associated_with_obesity

Lin, H. V., Frassetto, A., Kowalik, E. J., Nawrocki, A. R., Lu, M.M., Kosinski, J. R., ... Marsh, D. J. (2012). Butyrate and propionate protect against diet-induced obesity and regulate gut hormones via free fatty acid receptor 3-independent mechanisms. Plos ONE, 7(4), e35240. Retrieved from: https://www.ncbi.nlm.nih.gov/pmc/ articles/PMC3323649/

Li, Y., Innocentin, S., Withers, D. R., Roberts, N. A., Gallagher, A. R., Grigorieva, E. F., ... Veldhoen, M. (2011). Exogenous stimuli maintain intraepithelial lymphocytes via aryl hydrocarbon receptor activation. Cell, 147(3), 629-40. Retrieved from: https://www.cell.com/ cell/pdfExtended/S0092-8674(11)01136-6

Louis, S., Tappu, R. M., Damms-Machado, A., Huson, D. H., \& Bischoff, S. C. (2016). Characterization of the gut microbial community of obese patients following a weight-loss intervention using whole metagenome shotgun sequencing. PLOS ONE, 11(2), e0149564. Retrieved from: https://www.ncbi.nlm.nih.gov/ pmc/articles/PMC4769288/

Macfarlane, S., Macfarlane, G.T., (2003). Regulation of short-chain fatty acid production. Proceedings of the Nutrition Society, 62(1), 67-72. Retrieved from: https://www.cambridge.org/core/journals/ proceedings-of-the-nutrition-society/article/ regulation-of-shortchain-fatty-acid-production /9F72ACBE8EE4BE71616589CEE6A777D7

Miller, T. L., \& Wolin, M. J. (1979). Fermentations by saccharolytic intestinal bacteria. American Journal of Clinical Nutrition, 32(1), 164-172. Retrieved from: https://academic.oup.com/ajcn/ article-abstract/32/1/164/4666413?redirectedFr om=fulltext

Mohamad, N. E., Yeap, S. K., Lim, K. L., Yusof, H.M., Beh, B.K., Tan, S.W., ... Alitheen, N.B. (2015). Antioxidant effects of pineapple vinegar in reversing of paracetamol-induced liver damage in mice. Chinese Medicine, 10(3).
Retrieved from: https://www.ncbi.nlm.nih.gov/ pmc/articles/PMC4333164/

Moschen, A. R., Wieser, V., \& Tilg, H. (2012). Dietary factors: major regulators of the gut's microbiome. Gut and Liver, 6(4), 411-416. Retrieved from: https://www.ncbi.nlm.nih.gov/ pmc/articles/PMC3493718/pdf/gnl-6-411.pdf

Nie, Y., Luo, F., \& Lin, Q., (2018). Dietary nutrition and gut microflora: A promising target for treating diseases. Trends in Food Science and Technology, 75, 72-80. Retrieved from: https:// www.sciencedirect.com/science/article/abs/pii/ S0924224416303259

Nielsen, T. S., Theil, P. K., Purup, S., Nørskov, N.P., \& Knudsen, K.E., (2015). Effects of resistant starch and arabinoxylan on parameters related to large intestinal and metabolic health in pigs fed fat rich diets. Journal of Agricultural and Food Chemistry, 63(48), 10418-10430. Retrieved from: https://pubs.acs.org/doi/10.1021/acs. jafc. 5 b03372

Okazaki, Y., Sekita, A., Chiji, H., \& Kato, N., (2016). Consumption of lily bulb modulates fecal ratios of firmicutes and bacteroidetes phyla in rats fed a high-fat diet. Food Science Biotechnology, 25(S), 153-156. Retrieved from: https://link.springer.com/article/10.1007/ s10068-016-0112-9

Park, S., Ji., Y., Jung, H.Y., Park, H., Kang, J., Choi, S.H., ... Holzapfel. (2017). Lactobacillus plantarum HAC01 regulates gut microbiota and adipose tissue accumulation in a diet-induced obesity murine model. Applied Microbiology and Biotechnology, 101(4), 1605-1614. Retrieved from: https://link.springer.com/article/10.1007/ s00253-016-7953-2

Parnell, J.A., \& Reimer, R.A. (2013). Prebiotic fibers dose-dependently increase satiety hormones and alter Bacteroidetes and Firmicutes in lean and obese JCR:LA-cp rats. British Journal of Nutrition, 107(4),. 601-613. Retrieved from: https://www.ncbi.nlm.nih.gov/pmc/articles/ PMC3827017/pdf/nihms3660.pdf

Phillips, S.F., Pemberton, J.H., Shorter, R.G., \& Talbot, I.C. (1993). The Large Intestine: Physiology, Pathophysiology and Disease. New York: Raven Press Ltd, 51-92.

Power, S.E., O'Toole P.W., Stanton, C., Ross, R.P., \& Fitzgerald, G.F. (2014). Intestinal microbiota, diet and health, British Journal of Nutrition, 111(3), 387-402. Retrieved from: https://www. cambridge.org/core/journals/british-journal- 
of-nutrition/article/intestinal-microbiota-dietand-health/7DC9362520B265EB453771495E 520ABD

Prada, P.O., Hirabara, S. M., de Souza, C. T., Schenka, A.A., Zecchin, H.G., Vassallo, J., ... Saad, M.J. (2007). L-glutamine supplementation induces insulin resistance in adipose tissue and improves insulin signalling in liver and muscle of rats with diet- induced obesity. Diabetologia, 50(9), 1949-1959. Retrieved from: https://link. springer.com/article/10.1007/s00125-0070723-z

Qin, J., Li, R., Raes, J., Arumugam, M., Burgdorf, K.S., Manichanh, C., ... Wang, J. (2010). A human gut microbial gene catalogue established by metagenomic sequencing. Nature, 464, 5965. Retrieved from: https://www.nature.com/ articles/nature 08821

Rawls, J.F., Mahowald, M.A., Ley, R.E., \& Gordon, J.I. (2006). Reciprocal gut microbiota transplants from zebrafish and mice to germ-free recipients reveal host habitat selection. Cell, 127(2), 423-433. Retrieved from: https://www. ncbi.nlm.nih.gov/pmc/articles/PMC4839475/ pdf/nihms17202.pdf

Riva, A., Borgo, F., Lassandro, C., Verduci, E., Morace, G., Borghi, E., \& Berry, D. (2017). Pediatric obesity is associated with an altered gut microbiota and discordant shifts in Firmicutes populations. Environmental Microbiology, 19(1), 95-105. Retrieved from: https://www. ncbi.nlm.nih.gov/pmc/articles/PMC5516186/

Royall, D., Wolever, T.M., \& Jeejeebhoy, K.N. (1990). Clinical significance of colonic fermentation. American Journal of Gastroenterology, 85(10), 1307-12. Retrieved from: https://www.ncbi.nlm. nih.gov/pubmed/2220719

Robertfroid, M. (2007). Prebiotics: the concept revisited. Journal of Nutrition, 137(3), 830s-7s. Retrieved from: https://academic.oup.com/jn/ article $/ 137 / 3 / 830 \mathrm{~S} / 4664774$

Russell, D.A., Ross, R.P., Fitzgerald, G.F., \& Stanton, C. (2011). Metabolic activities and probiotic potential of bifidobacteria. International Journal of Food Microbiology, 149(88), 105. Retrieved from: https://www. sciencedirect.com/science/article/abs/pii/ S0168160511003382?via\%3Dihub

Salden, B.N., Troost, F.J., Wilms, E., Truchado, P., Vilchez-Vargas, R., Pieper, D.H., ... Masclee, A.A. (2018). Reinforcement of intestinal epithelial barrier by arabinoxylans in overweight and obese subjects: a randomized controlled trial arabinoxylans in gut barrier. Clinical Nutrition Journal, 37(2), 471-480. Retrieved from: https://www.clinicalnutritionjournal.com/ article/S0261-5614(17)30048-1/fulltext

Samuel, B.S., Shaito, A., Motoike, T., Rey F.E., Backhed, F., Manchester, J.K., ... Gordon, J.I. (2008). Effects of the gut microbiota on host adiposity are modulated by the shortchain fatty-acid binding $G$ protein-coupled receptor, Gpr41. Proceedings of the National Academy of Sciences of the United States of America, 105(43), 16767-16772. Retrieved from: https://www.ncbi.nlm.nih.gov/pme/ articles/PMC2569967/pdf/zpq16767.pdf

Schwiertz, A., Taras, D., Schäfer, K., Beijer, S., Bos, N.A., Donus, C., \& Hardt, P.D. (2010). Microbiota and SCFA in lean and overweight healthy subjects. Obesity, 18(1), 190-195. Retrieved from: https://onlinelibrary.wiley.com/ doi/abs/10.1038/oby.2009.167

Scott, K. P., Duncan, S. H., \& Flint, H. J. (2008). Dietary fibre and the gut microbiota. Nutrition Bulletin, 33(3), 201-211. Retrieved from: https:// onlinelibrary.wiley.com/doi/full/10.1111/ j.1467-3010.2008.00706.x

Semova, I., Carten, J.D., Stombaugh, J., Mackey, L.C., Knight, R., Farber, S.A., Rawls, J.F. (2012). Microbiota regulate intestinal absorption and metabolism of fatty acids in the zebrafish. Cell Host and Microbe, 12(3), 277-88. Retrieved from: https://www.ncbi.nlm.nih.gov/pmc/ articles/PMC3517662/pdf/nihms404058.pdf

Sonnenburg, J.L., \& Bäckhed, F. (2016). Dietmicrobiota interactions as moderators of human metabolism. Nature, 535(7610), pp. 56-64. Retrieved from: https://www.ncbi.nlm.nih.gov/ pmc/articles/PMC5991619/

Smith, C.J., \& Bryant, M.P. (1979). Introduction to metabolic activities of intestinal bacteria. American Journal of Clinical Nutrition, 32(1), 149-157. Retrieved from: https://academic.oup. com/ajcn/article-abstract/32/1/149/4666383?re directedFrom=fulltext

Spiller, G.A., Chernoff, M.C., Hill, R.A., Gates, J.E., Nassar, J.J., \& Shipley, E.A. (1980). Effect of purified cellulose, pectin, and a low-residue diet on fecal volatile fatty-acids, transit-time, and fecal weight in humans. American Journal of Clinical Nutrition, 33(4), 754-759. Retrieved from: https://academic.oup.com/ajcn/article-a bstract $/ 33 / 4 / 754 / 4692623$ ? redirectedFrom $=\mathrm{f}$ ulltext 
Stoupi, S., Williamson, G., Drynan, J.W., Barron, D., \& Clifford, M.N. (2010). A comparison of the in vitro biotransformation of (-)-epicatechin and procyanidin $\mathrm{B} 2$ by human faecal microbiota, Molecular Nutrition and Food Research, 54(6). Retrieved from: https://onlinelibrary.wiley.com/ doi/abs/10.1002/mnfr.200900123

Swann, J.R., Want, E.J., Geier, F.M., Spagou, K., Wilson, I.D., Sidaway J.E., ... Holmes, E. (2011). Systemic gut microbial modulation of bile acid metabolism in host tissues compartments. Proceedings of the National Academy of Sciences of the United States of America, 108(1), 4523-4530. Retrieved from: https://www.ncbi. nlm.nih.gov/pmc/articles/PMC3063584/pdf/ pnas.201006734.pdf

Tang, W.H.W., Kitai, T., \& Hazen, S.L. (2017). Gut microbiota in cardiovascular health and disease. Circulation Research, 120(7), 1183-1196. Retrieved from: https://www.ncbi.nlm.nih.gov/ pmc/articles/PMC5390330/pdf/nihms857163. pdf

Teixeira, T.F., Grześkowiak, L., Franceschini, S.C., Bressan, J., Ferreira, C.L., \& Peluzio, M.C. (2013). Higher level of faecal SCFA in women correlates with metabolic syndrome risk factors. British Journal of Nutrition, 109(5), 914-919. Retrieved from: https://www.cambridge.org/ core/journals/british-journal-of-nutrition/ article/higher-level-of-faecal-scfa-in-womencorrelates-with-metabolic-syndrome-risk-fac tors/83D7C406CBFE4AED235951478DBD 6BBB

Topping, D.L., \& Clifton, P.M. (2001). Short-chain fatty acids and human colonic function: roles of resistant starch and nonstarch polysaccharides. Physiological Reviews, 81(3), 1031-1064. Retrieved from: https://journals.physiology.org/ doi/pdf/10.1152/physrev.2001.81.3.1031

Turnbaugh, P.J., Ley, R.E., Mahowald, M.A., Magrini, V., Mardis, E.R., \& Gordon, J.I. (2006). An obesity-associated gut microbiome with increased capacity for energy harvest. Nature, 444:1027-1031. Retrieved from: https:// www.nature.com/articles/nature05414
Upadhyaya, B., McCormack, L., Fardin-Kia, A.R., Juenemann, R., Nichenametla, S., Clapper, J., ... Dey, M., (2016). Impact of dietary resistant starch type 4 on human gut microbiota and immunometabolic functions. Nature, 6, 28797. Retrieved from: https://www.ncbi.nlm.nih.gov/ pmc/articles/PMC4928084/pdf/srep28797.pdf

Verdam, F.J., Fuentes, S., de Jonge, C., Zoetendal, E.G., Erbil, R., Greve, J.W., ... Rensen, S.S. (2013). Human intestinal microbiota composition is associated with local and systemic inflammation in obesity, Obesity, 21(12), E607- E615. Retrieved from: https:// onlinelibrary.wiley.com/doi/epdf/10.1002/ oby. 20466

Vitaglione, P., Mennella, I., Ferracane, R., Rivellese, A.A., Giacco, R., Ercolin, D., ... Fogliano, V. (2015). Whole-grain wheat consumption reduces inflammation in a randomized controlled trial on overweight and obese subjects with unhealthy dietary and lifestyle behaviors: role of polyphenols bound to cereal dietary fiber. American Journal of Clinical Nutrition, 101(2), 251-61. Retrieved from: https://academic.oup. com/ajcn/article/101/2/251/4494380

Vogt, J. A., \& Wolever, T. M. S. (2003). Faecal acetate is inversely related to acetate absorption from the human rectum and distal colon. Journal of Nutrition, 133(10), 3145-3148. Retrieved from: https://academic.oup.com/jn/ article/133/10/3145/4687510

Wang, H., Hong, T., Li, N., Zang, B., \& Wu, X. (2018). Soluble dietary fiber improves energy homeostasis in obese mice by remodeling the gut microbiota. Biochemical and Biophysical Research Communication, 498(1), 146-151. Retrieved from: https:// www.sciencedirect.com/science/article/pii/ S0006291X18302407?via\%3Dihub

Whitney, E., \& Rolfes, S. R. (2013). Understanding Nutrition Thirteenth Edition. Belmont: Cengage Learning.

WHO. (2015). Obesity and overweight. Geneva: Media Centre World Health Organization. 